\title{
O PROGRAMA NACIONAL DE ALIMENTAÇÃO ESCOLAR (PNAE): ALIMENTAÇÃO E APRENDIZAGEM
}

\section{THE BRAZILIAN NATIONAL SCHOOL FEEDING PROGRAM (PNAE); FOOD FOR LEARNING}

\author{
Helen Gonçalves Romeiro Ferreira* \\ Rodrigo Gomes Alves** \\ Silvia Conceição Reis Pereira Mello***
}

\begin{abstract}
Resumo: Esse artigo apresenta uma reflexão sobre a história da merenda escolar no Brasil, ressaltando seu valor para os alunos da rede púbica de ensino. Sendo o Programa Nacional de Alimentação Escolar (PNAE) uma das políticas públicas mais importantes do país e da America Latina no combate à fome e à desnutrição, desenvolve a promoção da saúde nas escolas. As creches ou pré-escolas, o ensino fundamental e médio, bem como a educação indígena ou de áreas remanescentes de quilombos, alunos da educação especial, matriculados em escolas públicas e filantrópicas que participem do programa são o público alvo do $P N A E$, que oferece aos estudantes uma alimentação digna, colaborando com a aprendizagem e o desenvolvimento dos alunos e atuando na construção de hábitos alimentares saudáveis, além de prevenir a evasão escolar. Foi utilizada como base bibliográfica, uma literatura especializada, incluindo levantamento sobre a legislação vigente e artigos científicos selecionados por meio de busca nos bancos de dados do Scielo e Google acadêmico. O PNAE se destaca como um programa fomentador de identidades alimentares que tem como objetivo descaracterizar essa política tida como assistencialista, a qual acaba reduzindo a alimentação escolar como "comida para pobres".
\end{abstract}

Palavras-chave: Políticas Públicas. Alimentação Escolar. Desenvolvimento Local.

Abstract: This article presents a reflection on the history of school lunch in Brazil, highlighting its value for students in the public school network. Since the Brazilian National School Feeding Program (PNAE) is one of the most important public policies in the country and Latin America in the fight against hunger and malnutrition, it

\footnotetext{
* Mestranda no Programa de Pós - Graduação em Desenvolvimento Local (Mestrado Profissional) pelo Centro Universitário Augusto Motta - UNISUAM. Possui graduação em Licenciatura Plena em Ciências Biológicas pelo Centro Universitário Augusto Motta - UNISUAM.

** Mestrando do Programa de Pós-Graduação em Desenvolvimento Local pelo Centro Universitário Augusto Motta - UNISUAM. Pós-graduado em Gastronomia Funcional pelo Centro Universitário Augusto Motta, graduado em Gastronomia pelo Centro Universitário Augusto Motta e em Química Licenciatura Plena pela Universidade do Grande Rio.

*** Professora e orientadora do curso de Mestrado em Desenvolvimento Local e do curso de graduação em Ciências Biológicas do Centro Universitário Augusto Motta - UNISUAM. Doutora e Mestre em Higiene veterinária e processamento tecnológico de produtos de origem animal pela Universidade Federal Fluminense (UFF). Possui graduação em Zootecnia pela Universidade Federal Rural do Rio de Janeiro (UFRRJ).
} 
develops the promotion of health in schools. Kindergartens or pre-schools, elementary and secondary education, as well as indigenous or quilombian education, special education students enrolled in public and philanthropic schools participating in the program are the target audience of the PNAE, which offers students with a dignified diet, collaborating with students' learning and development, and working to build healthy eating habits, as well as preventing school dropouts. Literature was used as a bibliographical basis, through legislation, consulted in scientific articles, selected through search in the databases of Scielo and Google Scholar. Relevant topics were considered in the research, such as the PNAE as an element that foments food identities, focusing on discharacterizing this policy as a welfare state that turns out to be reducing school feeding as food for the poor.

Keywords: Public policy. School Feeding. Local Development. 


\section{INTRODUÇÃO}

O Programa Nacional de Alimentação Escolar (PNAE) é o maior programa de suplementação alimentar da América Latina contribuindo com a Segurança Alimentar e Nutricional e viabilizando a promoção do Direito Humano à Alimentação Adequada (DHAA) por meio da alimentação escolar, indo ao encontro das metas dos Objetivos de Desenvolvimento do Milênio (ODM) (LIBERMANN; BERTOLINI, 2015).

O PNAE tem como principal objetivo proporcionar aos estudantes uma alimentação digna, que garante minimamente, uma nutrição segura e de qualidade, o programa proporciona aos mesmos um exercício de cidadania e melhoria da qualidade de vida.

E para isso, o Programa Nacional de Alimentação Escolar tem como busca prestar auxílio financeiro adicional aos estados e municípios brasileiros com o objetivo de garantir uma refeição diária a cada aluno matriculado em escolas públicas e /ou filantrópicas. O programa oportuniza uma alimentação de qualidade para os estudantes resultando em uma melhor performance do aluno no ambiente escolar, visando reduzir a evasão escolar, auxiliando na construção de bons hábitos alimentares.

Para Silva Amparo-Santos e Soares (2018) quando foi criada a alimentação estudantil através das políticas de alimentação e nutrição objetivava a diminuição da desnutrição que, com o tempo, foi alcançada. Porém, o senso comum classificou a merenda como comida para alunos pobres e necessitados, o que deixou por um longo tempo esse programa com caráter assistencialista, ou seja, a ideia de que os pobres só iam à escola para comer, desmerecendo a real importância dessa política.

Por isso, esse estudo vem abordar a importância do PNAE para a inclusão e o desenvolvimento, educacional, biológico, cognitivo, social e inclusivo, além de promover o desenvolvimento local, através da agricultura familiar.

O PNAE atende a todas as escolas públicas, independentemente das condições socioeconômicas do estudante. Apesar disso, não exclui que a maior adesão de alunos que consomem a alimentação escolar é, com frequência, de estudantes com condições socioeconômicas mais baixas. De acordo com Valentim e 
outros (2017) esse contexto faz da merenda escolar, muitas vezes, a única refeição do dia.

Kirch e Copatti (2013) argumentaram que a fome e a desnutrição prejudicam a saúde, o crescimento e o desenvolvimento das ações cognitivas. A privação constante do mesmo acarreta em diminuição da glicose no sangue, o que contribui para a dificuldade de concentração.

Como Carvalho (2016) apontou que em idade escolar as crianças são as que mais necessitam de uma alimentação sadia, já que é nesse período que se desenvolvem psicologicamente e a partir do qual passam a desenvolver personalidade e hábitos alimentares.

A desnutrição pode comprometer o desenvolvimento do cérebro, podendo esse comprometimento ser temporário ou permanente. Já uma alimentação sadia e nutritiva proporciona uma melhor atividade cerebral, o que consolida a afirmativa de que a má nutrição é um dos fatores que impacta negativamente no desempenho escolar dos estudantes (CAVASSIN; PINHO, 2013).

Nesse contexto, a merenda escolar é de suma importância para a nutrição dos alunos ao contribuir para seu desenvolvimento fisiológico e cognitivo. Consequentemente, estudantes que se encontrem em estado de subnutrição não terão o mesmo desempenho que os indivíduos sadios.

As escolas, por exercerem um grande poder de sujeição, contribuem para a formação da identidade de cada indivíduo. Dessa forma, o indivíduo bem alimentado, participa de forma mais ativa nas atividades escolares, o que contribui de forma decisiva na construção da sua identidade. Possibilita que esse indivíduo seja ser influenciada pela inserção de alimentos saudáveis ao longo do desenvolvimento discente e essa construção de identidade instrumentalizar, assim, o indivíduo a ser questionador.

Valentim et al. (2017) destacaram que as condições estruturais das escolas como limpeza do refeitório, espaços adequados que comportem mesas e cadeiras suficientes contribuem para a maior adesão dos alunos a participarem da alimentação escolar e que a deterioração e a má gestão desses espaços são desmotivadores para os estudantes. Para o sucesso do programa, são necessárias 
ações em conjunto, englobando todos os atores, para promoverem melhorias e conservações dos ambientes escolares.

Considerada uma das políticas públicas mais antigas do Brasil, completando sessenta e quatro anos no ano de 2019, a merenda escolar destaca o quão necessário é o constante investimento e fiscalização para que cada vez mais estudantes possam continuar sendo contemplados.

\section{A MERENDA ESCOLAR NO BRASIL}

Nos anos de 1940, com o intuito de fornecer alimentação para os estudantes, algumas escolas começaram a promover uma organização interna para arrecadar renda e poder fomentar essa alimentação, assim surgindo as 'caixas escolares". O governo não subsidiava nenhum tipo de verba para as escolas destinarem a alimentação. (BRASIL, 2013a).

Porém, ao se constatar que o fornecimento de uma merenda aos estudantes contribuía para a sua permanência na escola, acabou por também contribuir para a redução da desnutrição infantil, uma séria preocupação do país na época.

Então, a partir da década de 50 o governo federal passou a fornecer merenda para todos os estudantes. Todavia, no início desse programa, as ações foram um pouco precárias, tendo em vista que o governo não conseguia abarcar todas as escolas e a oferta alimentar não provinha diretamente do governo, mas sim através de doações internacionais (BRASIL, 2013a).

Essas doações internacionais eram provenientes do financiamento feito pelo Fundo Internacional de Socorro à Infância (FISI) atualmente UNICEF, em que ocorria o repasse do leite em pó sobressalente, atribuído inicialmente, à campanha de nutrição materno-infantil. Devido a esse auxílio, o programa conseguiu se sustentar (BRASIL, 2018a).

Com isso, em 31 de março de 1955, o presidente Juscelino Kubitschek de Oliveira assinou o Decreto no. 37.106 (BRASIL, 1955), e através dele criou a Campanha da Merenda Escolar (CME). Ao longo dos anos, houve mudanças em suas denominações, até que em 1956, denominou-se Campanha Nacional de Merenda 
Escolar (CNME) na qual o intuito era de abranger todo o país. No ano de 1965, o CNME sofre outra alteração passando a se chamar Campanha Nacional de Alimentação Escolar (CNAE). O Brasil e organizações internacionais como Agência dos Estados Unidos para o Desenvolvimento Internacional (USAID) e Organização das Nações Unidas para Agricultura e Alimentação (FAO/ONU) apoiavam programas como Alimentos para a Paz, Programa de Alimentos para o Desenvolvimento, Programa Mundial de Alimentos (PMA) sendo um alicerce importante de consolidação da alimentação escolar. Já em 1976, se encontrava subsidiado pelo Ministério da Educação sendo gerido pela Campanha Nacional de Alimentação Escolar, que pertencia ao II Programa Nacional de Alimentação e Nutrição (PRONAN) que posteriormente em 1979, foi denominado Programa Nacional de Alimentação Escolar (PNAE) mais conhecido como merenda escolar (BRASIL, 2018a).

Segundo a Constituição Federal de 1988 capitulo II Art.6º é garantido a todos o direito à saúde, à educação e à alimentação. Nesse sentido, o direito à educação se encontra garantido no capitulo III seção I pelo art 205. Também se encontra no art. 208 inciso VII, que em todas as etapas da educação é dever do Estado fornecer material didático-escolar, transporte, alimentação e assistência à saúde (BRASIL, 1988).

E com a promulgação da Lei Orgânica de Segurança Alimentar e Nutricional no Brasil (LOSAN) foi possível criar o Sistema Nacional de Segurança Alimentar e Nutricional (SISAN). E é através do SISAN que o poder público e a sociedade civil organizada, caminham juntos em prol de elaborar e executar planos, programas e ações para garantir o direito humano à alimentação adequada (BRASIL, 2006).

\section{A IMPORTÂNCIA DO PNAE}

O PNAE é um Programa Nacional de Alimentação Escolar que oferece alimentação básica a todas as escolas publicas, além de promover ações de educação alimentar e nutrição aos estudantes (BRASIL, 2018b).

Consoante ao direito humano de acesso à alimentação, garantido pela Declaração Universal dos Direitos Humanos, da qual o Brasil é signatário, através do 
artigo $6^{\circ}$ da constituição federal de 1988 , o programa possui um importante papel no que tange a oferta de alimentação aos estudantes.

Como política pública, o Programa Nacional de Alimentação Escolar tem como dever amparar todos os estudantes, não ignorando qualquer necessidade especial que possa ser relacionada à alimentação, sem constrangimento ou discriminação (BRASIL, 2013a).

O reconhecimento internacional do PNAE é devido ao êxito do Programa de Alimentação Escolar Sustentável, que atende os Acordos Internacionais alicerçados com a Organização das Nações Unidas para Alimentação e a Agricultura (FAO) juntamente com o Programa Mundial de Alimentos (PMA), através da Agência Brasileira de Cooperação do Ministério das Relações Exteriores, com o intuito de corroborar com o desenvolvimento de Programas de Alimentação Escolar Sustentáveis em países da América Latina, seguindo os princípios da Segurança Alimentar e Nutricional e do Direito Humano a uma Alimentação Adequada (BRASIL, 2018a).

O PNAE tem como dever atender alunos de toda a escola de educação básica que abrange educação infantil, ensino fundamental, ensino médio e educação de jovens e adultos que obrigatoriamente devem estar matriculados em escolas públicas, filantrópicas ou entidades comunitárias que, por sua vez, também devem estar vinculadas ao poder público (BRASIL, 2018b). Entretanto, somente a partir de 2009, o programa passou a abarcar não somente as escolas filantrópicas e comunitárias, mas também aquelas localizadas em áreas de quilombolas e indígenas (BRASIL, 2013a).

A partir de 1998, o PNAE passou a ser gerido pelo Fundo Nacional de Desenvolvimento da Educação (FNDE), que se encontra sob a tutela do Ministério da Educação (MEC) e tem a responsabilidade de transferir a verba destinada pela União para a merenda escolar. O recurso passado pela União deve ser acrescido pelos estados e municípios, além do mesmo zelar pela diretriz, coordenação, fiscalização e execução do programa.

A execução desse programa se dá através das Secretarias Estaduais de Educação nos estados brasileiros e também no Distrito Federal. Já os municípios 
ficam sob os encargos das prefeituras municipais, além das escolas federais. Essas instituições, ao obterem esse dinheiro do FNDE, devem direcioná-lo para os custos alimentares dos alunos, tendo cada instituição a autonomia para definir como gastálo (BRASIL, 2013a).

Para se beneficiar desse programa, as escolas públicas devem estar cadastradas no Censo Escolar, que é realizado pelo Instituto Nacional de Estudos e Pesquisas Educacionais Anísio Teixeira (INEP/MEC). É importante ressaltar que as entidades filantrópicas ou comunitárias com algum vínculo público devem atender critérios da Resolução FNDE no 26/2013 para serem considerados aptos a participarem do programa (BRASIL, 2018b).

A sanção da Lei no 11.947, de 16 de junho (BRASIL, 2009a) ocasionou grandes progressos para o PNAE, possibilitando a expansão do Programa além das redes públicas de educação básica, sendo estendido para os alunos do Programa Mais Educação, e para jovens e adultos matriculados em escolas publicas. No mínimo $30 \%$ (trinta por cento) do dinheiro que é repassado ao FNDE precisam ser destinados à compra de produtos provenientes da agricultura familiar.

A incorporação, em 2013, de alunos que cursam o Atendimento Educacional Especializado (AEE) bem como os matriculados na Educação de Jovens e Adultos, modalidade semipresencial ou período integral, pode ser considerada uma grande vitória para o programa (BRASIL, 2018a).

Para manter o controle de todos esses módulos educacionais contemplados pelo PNAE, é realizado anualmente o Censo Escolar em todas as escolas brasileiras, entre os meses de janeiro e março. Os dados recolhidos são enviados para o INEP (Instituto Nacional de Estudo e Pesquisa) através de um formulário que deve ser entregue até a última quarta-feira do mês de maio, devido à data ser considerada o Dia Nacional do Censo Escolar (BRASIL, 2013a).

O INEP, por sua vez, tem como função receber esse formulário e após contabilizar, os dados do censo são divulgados no final de cada ano entre os meses de novembro e dezembro. Após a divulgação desses dados, o FNDE cataloga todas as escolas públicas que participaram do PNAE (BRASIL, 2013a). Já que há obrigatoriedade do preenchimento desses formulários, através do censo que o FNDE 
executa, é possível quantificar quanto cada escola vai receber e quantos alunos são beneficiados pelo PNAE.

Dos Santos, Costa e Bandeira (2016) discorrem sobre a necessidade que as escolas filantrópicas que desejam participar do programa têm de realizar cadastro no Conselho Nacional de Assistência Social (CNAS) para ofertarem alimentos aos seus alunos através da verba proveniente do PNAE.

Com a finalidade de obter um bom desenvolvimento do PNAE, as administrações municipais devem trabalhar em prol do programa, capacitando seus gestores sobre como utilizar os recursos mandados pela união através do censo escolar (FREITAS et al., 2013).

Em outras palavras, a aquisição dos insumos é feita através dos estados e municípios, que guiados pela Lei no 8.666, de 21/06/93 (BRASIL, 1993), devem tratar de licitações e contratos públicos. Toda verba do PNAE é exclusivamente direcionada para a compra de produtos alimentícios e qualquer gasto além, como infraestrutura para o funcionamento interno do programa, é de responsabilidade dos estados e município (DOS SANTOS; COSTA; BANDEIRA, 2016).

Uma das principais conquistas do PNAE veio no ano de 2006, quando foi estabelecida a obrigatoriedade da presença de um nutricionista como Responsável Técnico no quadro de funcionários de todas as Entidades Executoras. Isso possibilitou uma melhor qualidade de atendimento do PNAE para atingir seu objetivo. Outra conquista de grande relevância para o programa foi a parceria que o FNDE firmou com as Instituições Federais de Ensino Superior criando os Centros Colaboradores de Alimentação e Nutrição Escolar (CECANES) unidades de suporte que fomentam ações e projetos que atendem os interesses e necessidades do PNAE, além da fornecer capacitação para agentes promotores do programa (FNDE, 2018a).

Visto que o FNDE possui, incorporado à sua gestão federal, um profissional dessa área, a responsabilidade técnica da alimentação escolar de estados e municípios ficam também sob a tutela do PNAE (DOS SANTOS; COSTA; BANDEIRA, 2016). Ao se considerar que pode ser um custo a mais no orçamento, principalmente dos municípios, o nutricionista se encontra a nível estadual ou, caso seja acatado pelas instruções do PNAE, para a composição alimentar. 
Além de colaborar com o desenvolvimento biopsicossocial dos alunos, o PNAE, por subsequência, melhora o rendimento escolar, contribui para a assiduidade dos estudantes e participa, mesmo que indiretamente, na construção dos hábitos alimentares dos escolares (SILVA, AMPARO-SANTOS, SOARES, 2018).

O PNAE interfere secundariamente na economia local através da agricultura familiar. Wanderley (2009) descreveu a agricultura familiar como um modelo de produção que engloba economia doméstica, habitação, atividade profissional, patrimônio familiar e cria conexões socioeconômicas através de elos indissociáveis.

Uma das vantagens sobre as quais SANTOS et al. (2018) dissertaram é a de que o PNAE permite que o próprio produtor possa acessar tanto individualmente quanto por meio de organizações. Contudo, Rossetti, Winnie e Silva (2016) ressaltaram que para participar do programa, o produtor rural deve estar formalizado como pequeno produtor rural, o que o caracterizaria como agricultor familiar. Além de cumprir as exigências legais e sanitárias, que nem sempre condizem com a realidade do nível do empreendimento, essas exigências dificultam de certa forma a entrada do agricultor no programa.

\section{COMO A MERENDA CHEGA A ESCOLA}

O papel do governo federal é repassar a verba destinada à alimentação escolar a estados, municípios e escolas federais. Ao longo de todo o ano de 2018, o FNDE repassou $R \$ 2,79$ bilhões de reais para alimentação escolar, sendo esse recurso dividido e repassado em dez parcelas referentes aos meses de fevereiro a novembro, correspondendo aos duzentos dias letivos, sendo proporcional ao número de estudantes matriculados (BRASIL, 2018b). O valor repassado pelo Estado por aluno por dia letivo é calculado referente a cada modulo de ensino.

\section{Tabela 1 - Do Valor de Repasse da União por Aluno no Ano de 2018}

\begin{tabular}{cc|}
\hline INSTITUIÇÕES DE & VALOR REPASSADO \\
ENSINO & POR ALUNO \\
\hline Creches & $\mathrm{R} \$ 1,07$ \\
Pré-escola & $\mathrm{R} \$ 0,53$
\end{tabular}




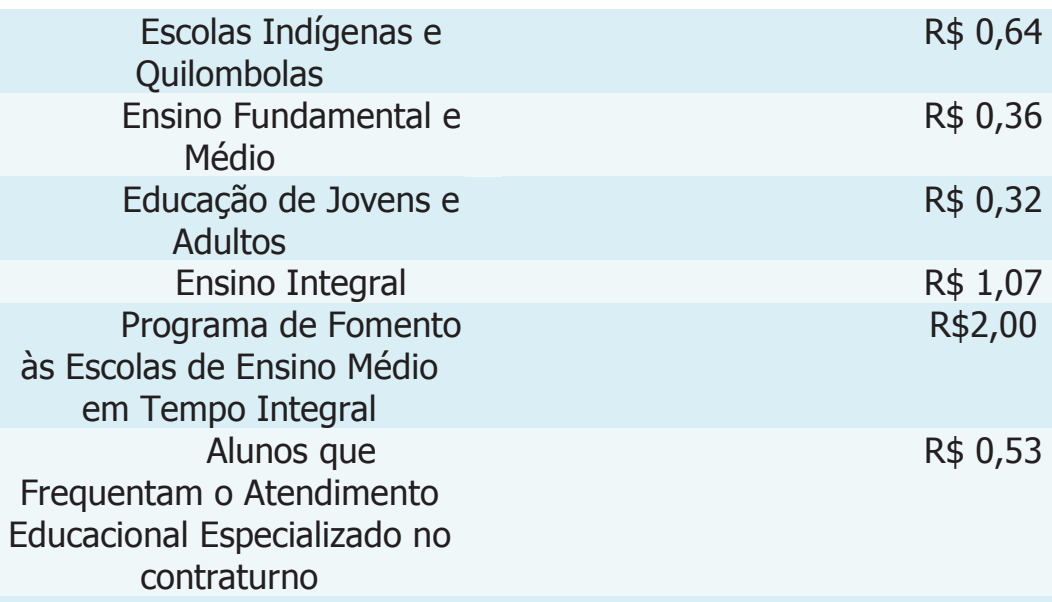

Fonte: (Tabela adaptada do valor repassado pela União por aluno. BRASIL, 2018c)

De acordo com a análise da tabela as discrepâncias entre as verbas das escolas indígenas e quilombolas em relação a outras escolas se devem a hábitos alimentares característicos das suas culturas.

Essa influência alimentar é muito particular nessas comunidades, o que pode onerar o valor da merenda. Além do mais, essa parcela da população, em geral, demonstra um número maior de casos de desnutrição, devido à conjuntura de insegurança alimentar e torna, muitas vezes, a merenda escolar a única refeição completa do dia (BRASIL, 2018b).

A verba repassada pela União é distribuída pelo PNAE diretamente aos estados e municípios, fiscalizada diretamente pela sociedade civil através do Conselho de Alimentação Escolar (CAE) também pelo Fundo Nacional de Desenvolvimento da Educação (FNDE) juntamente com o Tribunal de Contas da União (TCU) pela Controladoria Geral da União (CGU) e o Ministério Público (BRASIL, 2018b).

Do valor total destinado pela União, $70 \%$ (setenta por cento) deve ser executado unicamente na compra de provisões alimentares básicas, baseando se nos hábitos regionais (FNDE, 2018a) o que faz com que os estudantes conheçam, valorizem e tenham orgulho da sua cultura local, e não sejam tão influenciados pela alimentação contemporânea, muitas vezes, influenciadas pelas mídias. De acordo com (BRASIL, 2017) os estudantes do ensino fundamental e do ensino médio 
representam $71 \%$ (setenta e um por cento) dos estudantes atendidos pelo programa.

Até 1993, a compra da merenda escolar era centralizada pelo governo federal, ou seja, o mesmo delineava o cardápio, comprava os insumos e depois distribuía para os estados e municípios (BRASIL, 2018a). Com isso, havia a predominância de insumos industrializados para que se chegassem aptos para 0 consumo, e os alimentos mais sensíveis acabavam estragando no trajeto até o seu destino.

Devido a essas perdas em 1994 ocorreu a descentralização das compras dos insumos destinados ao programa, que através de convênios com os estados e municípios, juntamente com 0 abarcamento das Secretarias de Educação dos estados e do Distrito Federal, delegam a competência de adquirir os insumos alimentares para as redes e municípios das prefeituras que não aderiram à descentralização. Durante o período de 1994 a 1998 cresceu de 1.532 para 4.314 o número de municípios descentralizados computando mais de $70 \%$ (setenta por cento) dos municípios brasileiros (BRASIL, 2018a).

Desde essa descentralização, os estados e municípios passaram a decidir a melhor forma de gerir a receita destinada pelo PNAE. As maneiras possíveis de gerência são as seguintes: Centralizada, Descentralizada, Mista e Terceirização.

A gestão centralizada a Secretaria de Educação se responsabiliza pelos recursos, onde a mesma compra os insumos alimentares, objetiva o orçamento, projeta os cardápios, supervisionando a merenda, armazenamento dos estoques e a distribuição dos mesmos (DOS SANTOS; COSTA; BANDEIRA, 2016). Essa centralização pode ocorrer de três formas, o armazenamento dos alimentos se encontra em estoque central de onde é distribuído para as escolas, onde posteriormente serão preparadas as merendas, o próprio fornecedor entrega os insumos alimentares diretamente nas escolas, onde cada uma faz seu próprio armazenamento ou secretaria estadual de Educação ou a prefeitura possui uma cozinha no qual eles mesmos preparam os alimentos e depois distribuem para as escolas. 
Segundo (BRASIL, 2008) na gestão centralizada a verba é repassada diretamente para as entidades executoras pelo PNAE. Essas mesmas entidades são responsáveis pela compra e distribuição dos insumos para as escolas.

Facilitando o controle de gastos, minimiza os desperdícios já que as escolas não precisão ter grandes estoques, ainda levando em consideração de que quanto maior a compra, mais baixo é o preço dos insumos.

Na descentralização o FNDE repassa as verbas para as entidades executoras que por sua vez repassa para as escolas, que são responsáveis pela compra dos insumos alimentares (BRASIL, 2017b).

Como argumentam (BELIK; CHAIM, 2009) as escolas também podem se responsabilizar pelo armazenamento e preparo dos alimentos. O que conta como uma vantagem dessa gestão é a maior facilidade de se comprar produtos regionais, priorizando a agricultura familiar local, o que contribui para evitar o desperdício e melhorar a logística além de proporcionar um cardápio que provoque afetividade ao aluno.

Já na gestão mista há uma divisão de tarefas entre a Secretaria de Educação que se responsabiliza por comprar alimentos não perecíveis, posteriormente os distribuindo nas escolas e repassa o uma parcela proporcional por escola para a obtenção dos alimentos perecíveis (STOLASKI, 2005).

Os benefícios são muito semelhantes da gestão descentralizada, já que possibilita a aquisição mais facilitada de alimentos regionais, o que por si só valoriza a agricultura familiar local. Além disso, Dos Santos, Costa e Bandeira (2016) alega que o planejamento da merenda escolar conta com uma equipe qualificada para sua construção. Entretanto há a necessidade de um planejamento bem elaborado para o controle de compras, assim evitando o desperdício.

Tendo em vista a terceirização, a responsabilidade da compra de gêneros alimentícios fica por conta da Prefeitura ou pela Secretaria Estadual de Educação, no qual são também responsáveis pelo cardápio e a fiscalização. Desta forma, uma empresa contrata para a feitura dos alimentos, tendo as mesmas disponibilidades de espaço ou utilizando o próprio espaço físico das escolas (VALERIANI, 2011). 
Possibilitando uma variabilidade maior no cardápio, utiliza menos funcionários destinados na feitura dos alimentos.

Porém, podem elevar os custos alimentares que segundo Dos Santos, Costa e Bandeira (2016) que esse gasto com a contratação de empresas poderia ser implementado para melhorar a merenda e ou na melhoria da infraestrutura das cozinhas e refeitórios além da contratação de merendeiras. A terceirização acaba por ser mais usada em escolas de pequeno porte e ou que não possuam estrutura física necessária para abrigar uma cozinha.

Esses vários modelos de gestão fazem com que a prestação de contas seja de extrema importância para o bom funcionamento do programa. As gestões mistas ou descentralizadas devem prestar contas a suas unidades executoras, sobre as aquisições dos insumos alimentares, tornando as escolas corresponsáveis pela gestão. As unidades executoras prestarão contas ao FNDE, através do Sistema de Gestão de Prestação de Contas - Contas Online (SiGPC) (BRASIL, 2015). Independentemente da gestão utilizada pelos estados e municípios, existem algumas orientações que regem o programa que devem seguidas.

Por meio da resolução FNDE n 26, de 2013 consolidando o Programa, a Educação Alimentar e Nutricional (EAN) compactua com políticas públicas relacionadas à Segurança Alimentar e Nutricional (SAN) juntamente com o Plano Nacional Combate à Obesidade e do Plano de Ações Estratégicas para combater Doenças Crônicas não Transmissíveis (DCNT) (BRASIL, 2018a).

É através da Lei no 11.947, de 16/06/2009 (BRASIL, 2009a), que fica determinado que $30 \%$ do total do valor repassado pelo FNDE no âmbito do PNAE devem ser investidos na compra direta de produtores da agricultura familiar, o que estimula o desenvolvimento econômico e sustentável das comunidades e favorece o consumo de frutas e verduras na alimentação escolar (BRASIL, 2009a).

Em conjunto com a Resolução no 38/2009M, que torna obrigatório servir frutas e verduras no cardápio semanal da alimentação escolar (BRASIL, 2009b).

Essas diretrizes que o programa traz ajudam aos profissionais da nutrição dos municípios a criarem cardápios mais ricos e nutritivos, que possam contemplar 
todos os alunos e a inserção da obrigatoriedade e frutas e verduras nos cardápios estimula a agricultura familiar, além de valorizar a sazonalidade local.

MELÃO (2012) ressalta que o controle de qualidade dos produtos é de responsabilidade da Vigilância Sanitária. Ou seja, todos os produtos alimentares devem seguir sua legislação especifica, assim garantindo a integridade e saúde dos estudantes.

A introdução de frutas e verduras e o incentivo ao consumo de alimentos mais saudáveis diminuem os riscos de se desenvolver doenças como diabetes, câncer, obesidade além de problemas cardíacos segundo (KIRCH; COPATTI, 2013). Doenças que cada vez mais se desenvolvem na menor idade influenciados pela má alimentação.

Através da Resolução/CD/FNDE no38, de 16 de julho de 2009 (BRASIL, 2009b) ocorreu um incentivo maior a agricultura familiar, que promove a economia local e valorização alimentos típicos de cada região. Além de propiciar a inclusão de alimentos não usuais que são produzidos nas localidades, que comumente não são consumidos por questões econômicas ou falta de habito familiar.

\section{A PRÁTICA ALIMENTAR NO CARDAPIO ESCOLAR}

Segundo (SILVA, AMPARO-SANTOS, SOARES, 2018) a alimentação escolar é uma denominação para um conjunto de refeições oferecidas pelo PNAE através das escolas publicas brasileira. Mostrando que a merenda na hora do intervalo já se tornou uma pratica que constitui o meio escolar, ajudando a esses alunos a criarem hábitos alimentares.

A globalização estimula cada vez mais o consumo de alimentos industrializados, consequentemente acabam influenciando nas escolhas do dia-a-dia, dificultando a manutenção da cultura alimentar de cada região. Além disso, o consumo excessivo de alimentos industrializados possui relação com algumas doenças crônicas não transmissíveis que vêm crescendo em crianças e adolescentes (CAMOZZIL et al., 2015). 
O grande desafio da merenda escolar é aceitação dos alunos, além dos professores incentivarem o consumo de alimentos saudáveis são as manipuladoras da alimentação popularmente conhecidas como merendeiras. Elas que são responsáveis pelos estratagemas para atrair os alunos a provarem novas receitas. Entretanto, essas estratagemas, muitas vezes, não são planejadas, o que acaba indo de encontro com políticas promotoras da saúde, e geralmente sem nenhum preparo técnico, já que comumente se visa valorizar a culinária regional e a palatabilidade do aluno ao alimento, em vez do seu caráter nutricional. Esse ponto de vista se dá ao senso comum que uma alimentação caseira e alimentos com valor afetivo da cultura local são considerados saudáveis (CAMOZZIL et al., 2015).

Kirch e Copatti (2013) alertaram que as merendeiras deveriam receber cursos de capacitação nutricional, além de aprenderem técnicas de aproveitamento integral de alimentos.

José Fernando Uchôa, Diretor de Ações Educacionais do FNDE e responsável pela execução do PNAE e acredita que se deve investir mais nos atores que estão envolvidos na realização do programa, alegando que os mesmos têm um olhar mais sensível sobre o programa e alcançam todas as pessoas envolvidas para que trabalhem em conjunto (BRASIL, 2018d).

Um ponto bastante discutido na merenda escolar está associado a regionalismo, aspecto, sabor, sociabilidade, familiaridade e estranhamento. Onde algumas combinações alimentares e o horário que a merenda é servida colidem com a cultura local onde está sendo oferecido e acabam gerando estranheza, mesmo sendo alimentos conhecidos, o horário em que são ofertados tornam-se atípicos. Afinal ainda está bastante enraizada de que a comida deve ser primeiramente aprazível e depois nutritiva (FREITAS et al., 2013) o que mostra a necessidade de um planejamento educacional constante sobre tópicos relativos à higienização dos alimentos, à preparação, à criação do cardápio e às maneiras de preparo. Os responsáveis pela manipulação dos alimentos procuram primar por preparações saudáveis e variadas, respeitando o regionalismo, não deixando de se preocupar em restringir o excesso de gordura, açúcar ou sal (CAMOZZIL et al., 2015). 
De acordo com a Resolução CD/FNDE no 26, de 17 de junho de 2013 (BRASIL, 2013b) a escola deve oferecer no mínimo três porções de frutas e hortaliças semanalmente e que as bebidas oferecidas devem ser à base de frutas. A alimentação servida deve seguir os seguintes critérios: Creches ou pré-escolas em período parcial devem oferecer minimamente $30 \%$ (trinta por cento) das necessidades nutricionais, na qual essa quantidade pode ser distribuída em no mínimo em duas refeições, ou $70 \%$ (setenta por cento) das necessidades nutricionais, quando há a oferta de três refeições, para as creches ou pré-escolas em período integral incluindo comunidades indígenas ou áreas remanescentes de quilombos.

Em escolas localizadas em comunidades indígenas ou em áreas remanescentes de quilombos, a merenda escolar deve ofertar minimamente $30 \%$ (trinta por cento) das necessidades nutricionais diárias, por refeição distribuída, exceto creches.

Nas escolas básicas exceto creches, a alimentação servida deve atender minimamente $20 \%$ (vinte por cento) das necessidades nutricionais diárias quando se é ofertada uma refeição em períodos parciais e 30\% (trinta por cento) das necessidades diárias ao se ofertar duas ou mais refeições.

Os alunos participantes do Programa Mais Educação devem receber uma alimentação com no mínimo $70 \%$ (setenta por cento) das necessidades nutricionais, podendo ser distribuída em três ou mais refeições para os matriculados em escolas de tempo integral. Esse aumento das necessidades diárias em escolas ajuda a minimizar a desnutrição e a desigualdade social (BRASIL, 2013b). Principalmente em comunidades indígenas ou áreas remanescentes de quilombos.

Além de a escola ser uma unidade promotora de saúde, possui um papel importante na formação cidadã dos alunos. Essa formação se baseia no estímulo da autonomia, aprendendo a exercitar direitos e deveres, além de cultivar bons comportamentos em sociedade. A promoção da alimentação saudável impacta na saúde, na autoestima dos estudantes e, consequentemente, no desenvolvimento de habilidades. O problema é que, muitas vezes, a merenda escolar é usada como um 
subterfúgio para diminuir a evasão escolar que, particularmente, é mais elevada com alunos de baixa renda (CAMOZZIL et al., 2015).

E muitas vezes a merenda escolar acaba por ser a única alimentação que esses alunos têm ao longo do dia, com isso garantindo a permanência deles na escola. Mostrando como o PNAE atua diretamente sobre a evasão escolar e na diminuição dos casos de desnutrição, fazendo o ambiente estudantil um refugio para esses estudantes.

Por isso, a necessidade do cardápio escolar deve contemplar todos os grupos alimentares, cereais e tubérculos, verduras, frutas e hortaliças, leite e derivados, carnes e ovos e leguminosas. Adaptar o cardápio a sazonalidade local garante alimentos sempre frescos e nutritivos, de menor custo, devido aos ciclos naturais e agrícolas favorecendo a compra de alimentos de agricultores familiares da região (RAMOS, 2011).

Segundo Silva, Amparo-Santos e Soares (2018) as escolas brasileiras têm predileção pelo preparo de alimentos salgados, onde a base desses pratos é arroz e feijão. Alegando que essa predileção se dá pela associação cultural alimentar nacional, que vem desde a infância. Sendo considerado um alimento de identidade nacional a combinação de arroz e feijão por si só traz o apelo cultural, o que resulta em um conforto alimentar. Facilitando a aceitação do alimento, mesmo em horas não costumeiras, como o período do intervalo que corresponde as dez horas da manhã, três horas da tarde sete horas da noite.

Valentim et al. (2017) acreditam que a merenda escolar pode não atender as preferências alimentares dos alunos. E essa hipótese se respalda pelo grande número de estudantes que não consomem a merenda escolar por darem preferência a outros alimentos, e em sua maioria esses estudantes são adolescentes. Esses alimentos competidores da merenda escolar não estão diretamente somente associados a cantinas comerciais, os pontos de vendas próximos as escolas tendem a ter sua parcela de contribuição.

Cervato-Mancuso et al. (2013) apontaram que o padrão da merenda escolar vem, ao longo dos anos, mudando no Brasil, usando cada vez menos produtos industrializados para dar preferência para alimentos in natura. 
Os alimentos processados não são muito bem vistos pelo Brasil, no preparo da alimentação escolar, devido aos métodos de processamento utilizados na fabricação que acabam por alterar de maneira desfavorável a sua composição nutricional, devido a grande adição de sal ou açúcar que são submetidos. Por isso os mesmos devem ser usados em pequenas quantidades, e em conjunto com alimentos saudáveis (BRASIL, 2014).

Em alguns estados do Brasil as cantinas escolares são proibidas de venderem alimentos não saudáveis como salgadinhos fritos, bebidas com alto teor calórico, doces, refrigerantes, sucos industrializados e pipoca doce (VALENTIM et al., 2017). São medidas que dificultam o acesso a alimentos não saudáveis, entretanto o estudante ainda pode adquirir os mesmos em pontos de vendas nas proximidades escolares, ou trazer de casa.

A maioria desses alimentos competidores da merenda escolar é considerada como alimento ultra processado, se encontra facilmente inserido na cultura e por isso, seu consumo acaba fazendo parte do cotidiano. Por meio de sua composição nutricional desbalanceada são alimentos que acabam por favorecer a propensão de doenças cardíacas, diabetes e vários tipos de câncer, além de contribuir para aumentar o risco de deficiências nutricionais e aumentando o risco de obesidade (BRASIL, 2014).

\section{CONSIDERAÇÕES FINAIS}

O Programa Nacional de Alimentação Escolar (PNAE) já passou por várias adaptações e denominações até chegar ao modelo que se tem hoje. Porem o mesmo sempre manteve o objetivo de fornecer aos estudantes de escola publica uma alimentação segura e de qualidade. O PNAE por muitos anos foi menosprezado como uma política para pobre ir para a escola, mas ao longo de pouco mais de 60 anos, e por meio de muita luta, se tornou referência mundial em programas de alimentação escolar sendo reconhecido como o maior da América Latina.

O programa abarca toda a educação básica, educação indígena, áreas remanescentes de quilombos, alunos da educação especial, escolas filantrópicas, 
alunos do Programa Mais Educação, e para jovens e adultos matriculados em escolas publicas.

E por meio da merenda escolar, que o PNAE conseguiu manter todos esses estudantes na escola, diminuir a desnutrição, melhorar o desempenho escolar, contribuir para o desenvolvimento fisiológico e cognitivo, construir hábitos saudáveis e formar cidadãos.

Em segundo plano o PNAE promove o desenvolvimento econômico local estimulando a agricultura familiar. Preservando a cultura alimentar de cada região, o que diminui a interferência de alimentos industrializados e estimula o consumo de uma alimentação saudável.

Além de criar hábitos alimentares sadios, que por consequência, diminuem as chances de doenças crônicas não transmissíveis como dos problemas cardíacos, diabetes e vários tipos de câncer, também contribui para diminuir deficiências nutricionais e o risco de obesidade. Doenças que estão cada vez mais presente nos jovens devido a má alimentação.

Conclui-se que o PNAE é uma política pública de alimentação escolar, que proporciona aos estudantes uma alimentação saudável e digna que contempla minimamente as necessidades diárias nutricionais. E através dessa merenda consegue diminuir o número de evasão dos alunos, melhorando o rendimento educacional, promovendo saúde e estimulando o desenvolvimento econômico social e local.

Todavia, não se pode excluir que na realidade muitos estudantes frequentam as escolas unicamente por ser, muitas vezes, o único lugar onde podem ter uma nutrição satisfatória, o que leva à necessidade de que o governo continue a investir em políticas públicas que possam melhorar a qualidade de vida dos cidadãos.

\section{REFERÊNCIAS}

BELIK, W.; CHAIM, N. A.; O programa nacional de alimentação escolar e a gestão municipal: eficiência administrativa, controle social e desenvolvimento local. Rev. Nutr., Campinas, v. 22, n. 5, p. 595-607, set./out. 2009. 
BRASIL. [Contituição (1988)]. Constituição da República Federativa do Brasil: atualizada até a EC n. 99/2017. Brasília: Supremo Tribunal Federal, Secretaria de Documentação, 2018. Disponível em:

https://www.stf.jus.br/arquivo/cms/legislacaoConstituicao/anexo/CF.pdf. Acesso em: 3 abr. 2019. ISBN: 978-85-61435-84-4.

BRASIL. Presidência da República. Decreto no 37.106, de 31 de Março de 1955. Institui a companhia da Merenda Escolar. Disponível em: https://www2.camara.leg.br/legin/fed/decret/1950-1959/decreto-37106-31-marco1955-332702-publicacaooriginal-1-pe.html. Acesso em: 5 out. 2018.

BRASIL. Presidência da República. Lei No 8.666, de 21 de junho de 1993. Regulamenta o art. 37, inciso XXI, da Constituição Federal, institui normas para licitações e contratos da Administração Pública e dá outras providências. Disponível em: http://www.planalto.gov.br/ccivil_03/LEIS/L8666cons.htm. Acesso em: 5 out. 2018.

BRASIL. Presidência da República. Lei no 11.346, de 15 de setembro de 2006. Cria o Sistema Nacional de Segurança Alimentar e Nutricional - SISAN com vistas em assegurar o direito humano à alimentação adequada e dá outras providências. Disponível em: http://www.planalto.gov.br/ccivil_03/_Ato20042006/2006/Lei/L11346.htm. Acesso em: 4 abr. 2019.

BRASIL. Ministério da Educação (MEC). Programa Nacional de Formação Continuada a Distância nas Ações do FNDE. 2.ed., atual. Brasília: MEC, FNDE, SEED, 2008.

BRASIL. Presidência da República. Casa Civil. Subchefia para Assuntos Jurídicos. Lei no 11.947, de 16 de junho de 2009. 2009a. Dispõe sobre o atendimento da alimentação escolar e do Programa Dinheiro Direto na Escola aos alunos da educação básica. Disponível em:

http://www.planalto.gov.br/ccivil_03/_ato20072010/2009/lei/l11947.htm. Acesso em: 5 out. 2018.

BRASIL. Ministério da Educação. Resolução/CD/ FNDE no 38, de 16 de julho de 2009. 2009b. Dispõe sobre o atendimento da alimentação escolar aos alunos da educação básica no Programa Nacional de Alimentação Escolar (PNAE). Disponível em: https://www.fnde.gov.br/acesso-a-

informacao/institucional/legislacao/item/3341-resolu\%C3\%A7\%C3\%A3o-cd-fnden\%C2\%BA-38-de-16-de-julho-de-2009. Acesso em: 4 abr. 2019.

BRASIL. Ministério da Educação. Secretaria de Educação Profissional e Tecnológica. Políticas de Alimentação Escolar / Lorena Gonçalves Chaves Medeiros. 4. ed. atual. rev. Cuiabá: Universidade Federal de Mato Grosso, Rede e-Tec Brasil, 2013a. ISBN 85-86290. 
BRASIL. Resolução CD/FNDE no 26, de 17 de junho de 2013. 2013b. Dispõe sobre o atendimento da alimentação escolar aos alunos da educação básica no âmbito do Programa Nacional de Alimentação Escolar - PNAE. Disponível em: HTTPS://www.fnde.gov.br/fndelegis/action/UrlPublicasAction.php?acao=getAtoPublic o\&sgl_tipo $=$ RES\&num_ato $=00000026 \&$ seq_ato $=000 \& v l r \_a n o=2013 \& s g l$ orgao $=F N D$ E/MEC. Acesso em: 15 dez 2018.

BRASIL. Ministério da Saúde. Secretaria de Atenção à Saúde. Departamento de Atenção Básica. Guia alimentar para a população brasileira / Ministério da Saúde, Secretaria de Atenção à Saúde, Departamento de Atenção Básica. 2. ed. Brasília: Ministério da Saúde, 2014. ISBN 978-85-334-2176.

BRASIL. Governo do Brasil. Programa nacional de alimentação escolar completa 62 anos. 2017a. Disponível em: http://www.brasil.gov.br/noticias/educacao-e-ciencia/2017/03/programa-nacionalde-alimentacao-escolar-completa-62-anos. Acesso em: 10 nov. 2018.

BRASIL. Tribunal de Contas da União. Cartilha para conselheiros do Programa Nacional de Alimentação Escolar (PNAE). Brasília: TCU, 2017b.

BRASIL. Ministério da Educação. Cartilha Nacional da Alimentação Escolar. Brasília: [s.n.], 2015. Disponível em:

https://www.fnde.gov.br/programa/pnae/penae-area-para-gestores/penae-manuaiscartlhas/item/6820-cartilha-penae-2015 Acesso em: 06 dez. 2018.

BRASIL. Ministério da Educação. Programa de suplementação: sobre o PNAE. 2018b. Disponível em: http://www.fnde.gov.br/programas/pnae. Acesso em: 10 nov. 2018.

BRASIL. Ministério da Educação. Programa de suplementação, PNAE Histórico. 2018a Disponível em: http://www.fnde.gov.br/programas/programassuplementares/pnae-sobre-o-programa/pnae-historico. Acesso em: 10 nov. 2018.

BRASIL. Ministério da Educação. Repasses de Recursos- FNDE repassa R\$ 489 milhões para alimentação e transporte escolar. 2018c. Disponível em: https://www.fnde.gov.br/acesso-a-informacao/institucional/area-deimprensa/noticias/item/12066-fnde-repassa-r\$-489-milh\%C3\%B5es-paraalimenta\%C3\%A7\%C3\%A3o-e-transporte-escolar. Acesso em: 7 dez. 2018.

BRASIL. Ministério da Educação. Referência na ONU, Programa Nacional de Alimentação Escolar completa 63 anos. 2018d. Disponível em: http://portal.mec.gov.br/busca-geral/384-noticias/fnde-1801140772/62281referencia-na-onu-programa-nacional-de-alimentacao-escolar-complet\%E2\%80\%A6. Acesso em: 10 nov. 2018. 
CARVALHO, A. P. L. S. Importância da Alimentação para Melhorias na Aprendizagem de Crianças em Unidades Públicas De Ensino: Revisão Integrativa. Revista Somma, Teresina, v.2, n.2, p.74-83, jul./dez. 2016.

CAMOZZIL, A. B. et al. O. Promoção da Alimentação Saudável na Escola: realidade ou utopia? Cad. Saúde Colet, Rio de Janeiro, v. 23 n. 1, p. 32-37, 2015. DOI: 10.1590/1414-462X201500010006.

\section{CAVASSIN, P. M.; PINHO, K. E. P. Influência da Alimentação no}

Desenvolvimento do Aluno e na Aprendizagem Escolar. Curitiba: SEP, 2013. v. 1. (Cadernos PDE). Disponível em:

http://www.diaadiaeducacao.pr.gov.br/portals/cadernospde/pdebusca/producoes_pd e/2013/2013_utfpr_cien_artigo_paulo_martins_cavassin.pdf. Acesso em: 4 abr. 2019.

CERVATO-MANCUSO, AM.; WESTPHAL, M. F.; ARAKI, E. L.; BOGUS, C. M. O papel da alimentação escolar na formação dos hábitos alimentares. Ver. Paul. Pediatr., São Paulo, v. 31, n. 3, p. 324-330, 2013.

DOS SANTOS, S. R.; COSTA, M. B. S.; BANDEIRA, G. T. P. As formas de gestão do programa nacional de alimentação escolar (PNAE). Revista de Salud Pública, Bogotá, v.18 n. 2, p. 311-322, abr. 2016. DOI:

http://dx.doi.org/10.15446/rsap.v18n2.41483.

FREITAS, M. C. S. et al. Escola: lugar de estudar e de comer. Ciência \& Saúde Coletiva, Rio de Janeiro, v. 18, n. 4, p. 979-985, 2013.

LIBERMANN, A. P; BERTOLINI, G. R. F. Tendências de pesquisa em políticas públicas: uma avaliação do Programa Nacional de Alimentação Escolar - PNAE.

Ciência \& Saúde Coletiva, v. 20, n. 11, p. 3533-3546, 2015. DOI: 10.1590/1413812320152011.16822014.

KIRCH, A. T.; COPATTI, L. C. O Direito à Alimentação De Crianças e Adolescentes: uma discussão acerca do papel dos poderes do Estado e da sociedade civil em prol da concretização. Revista de Estudos Jurídicos UNESP, São Paulo, v. 17, n. 26. 2013. Disponível em:

https://ojs.franca.unesp.br/index.php/estudosjuridicosunesp/article/view/839. Acesso em: 3 dez. 2018.

MELÃO, I. B. Produtos Sustentáveis na Alimentação Escolar: O PNAE no Paraná. Cad. IPARDES, Curitiba, PR, v.2, n.2, p. 87-105, jul./dez. 2012.

RAMOS, M. O. "As crianças estão se sentindo importantes": Avanços na alimentação escolar a partir da lei 11. 947/2009 e da compra da Agricultura familiar. Revista Trajetória: Multicursos, Rio Grande do Sul: Porto Alegre. 2011. 
ROSSETTIL, F. X.; WINNIE, LoWaiYee; SILVA, M.V. O Programa Nacional de Alimentação Escolar (PNAE) e o desafio da aquisição de alimentos regionais e saudáveis. Segurança Alimentar e Nutricional, Campinas, v. 23, n. 2, p. 912923, 2016. DOI: http://dx.doi.org/10. 20396/san.V23i2. 8647528.

SANTOS, L, F.; DE CAMPOS, A. P. T.; FERREIRA, M. A. M.; DE FREITAS, A. F. Implicações das redes sociais para a acesso às políticas públicas: análise em cooperativas da agricultura familiar. Revista Brasileira de Gestão e

Desenvolvimento Regional, Taubaté, SP, v. 14, n. 1, p. 329-353, jan./abr. 2018.

SILVA, E. O.; AMPARO-SANTOS, L.; SOARES, M. D. Alimentação escolar e constituição de identidades dos escolares: da merenda para pobres ao direito à alimentação. Cad. Saúde Pública, Rio de Janeiro, v. 34, n. 4, 2018. DOI: 10.1590/0102-311X00142617.

STOLASKI, M.; Caminhos da Alimentação Escolar no Brasil: análise de uma política pública no período de 2003-2004. 2005. Dissertação (Mestrado em Desenvolvimento Econômico com ênfase em Políticas Públicas) - Setor de Ciências Sociais Aplicadas da Universidade do Paraná, Curitiba, 2005.

VALENTIM, E. A. et al. Fatores associados à adesão à alimentação escolar por adolescentes de escolas públicas estaduais de Colombo, Paraná, Brasil. Cad. Saúde Pública, Rio de Janeiro, v. 33, n. 10, 2017.

VALERIANI, T, S, M.; A gestão escolarizada do Programa de alimentação Escolar no Estado de Goiás. 2011. Dissertação (Mestrado em Ciências) - Escola Superior de Agricultura "Luiz Queiroz" da Universidade de São Paulo, Piracicaba, 2011.

WANDERLEY, M. de N. B. 0 mundo rural como um espaço de vida: reflexões sobre a propriedade da terra, agricultura familiar e ruralidade. Porto Alegre: UFRGS, 2009. (Série Estudos Rurais). 